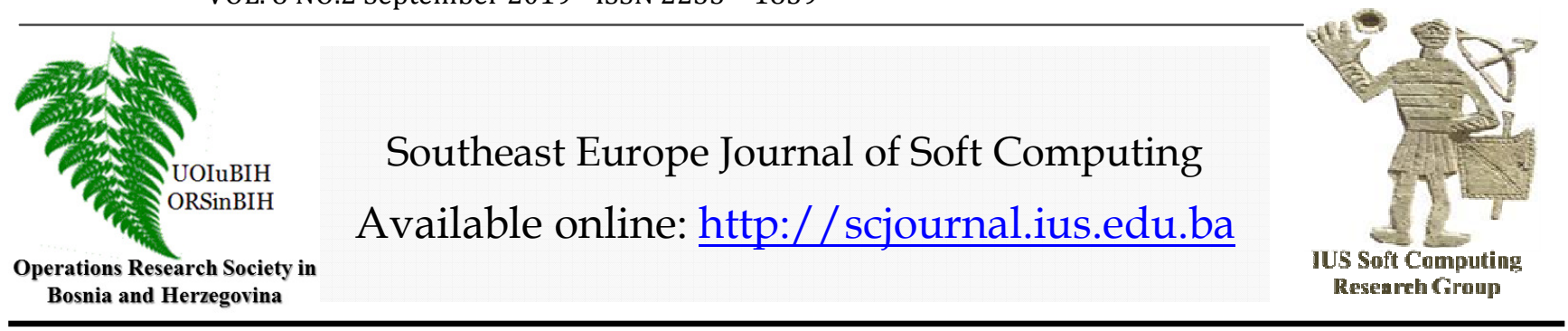

\title{
The Impact of Human Capital on Product Innovation
}

\author{
A. W. Aidoo \\ Faculty of Business and Administration, \\ International University of Sarajevo, \\ Hrasnicka Cesta 15, Ilidža 71210 Sarajevo, \\ Bosnia and Herzegovina \\ aaidoo@student.ius.edu.ba
}

\section{Article Info}

Article history:

Article history:

Article received on June 1, 2019

Received in revised form: September 12,2019

Keywords:

Research and development; formal training; formal education; product innovation; small and medium scale enterprises

\begin{abstract}
This research study is focused on the influence of human capital on innovation in SMEs. The human capital factors are the independent variables: employee's education, employee's development, and employee's challenge, while the dependent variable is product innovation. Data of manufacturing and service firms in the economies of Africa and the Middle-East are taken from the World Bank Enterprise Survey database through a stratified random sampling. A sampled of 33,977 firms are observed in 53 countries. The methodology employed in this study is the quantitative research approach. A pairwise correlation, regression model and forecasting model are used for the analyses of the data. The findings from the analyses show satisfactory levels of significance with $\mathrm{p}$ values below $1 \%$ even though not all the Pearson correlation coefficients of the independent variables with the dependent variable are high. The goodness-of-fit, in terms of R-squared, Root MSE, and mean percentage error, found from the regression of human capital with product innovation is slightly poor. This is due to the loose relation between independent and dependent variables in real life and partly to the data available for this research. However, human capital acquired from skilled and formal training of employees has a more positive and significant influence on SMEs to innovate products. The findings have implications on managerial decisions and governmental policies. The results also give insight into the limitations of the research and areas for further investigations.
\end{abstract}

\section{INTRODUCTION}

The basis of the competitiveness of a firm is the ability to create and implement sustainable innovations, and occurrence of it is largely dependent on the performances of the employees, managers, and employers of the firm in question. The focus of this research is on the influence of human capital of small and medium sized enterprises
(SMEs) on their product innovation performance. For this study, SMEs are described as firms with a total number of permanent employees of up to 99. The firms considered in this research are taken from geographical regions of Africa and the Middle-east.

Innovation plays a critical role in enhancing and driving economic growth and development in every country. More 
importantly, it is a fundamental tool for creating and driving innovation and improving a country's economic growth and development (Schumpeter, 1934; Sundbo, 1998; Galunic \& Rodan, 1998). Research by Miller (1983) demonstrates that for entrepreneurship to survive in a competitive industry, it should have the sound features of risk-taking and radical innovation. Therefore, it has become imperative to start the concept of innovation implementation at the SMEs stage in order to ensure sustainability in the market competition and growth in the long-run (Miller, 1983; Covin \& Slevin, 1991; Hitt, Hoskisson, Johnson \& Moesel, 1996; Dougherty \& Hardy, 1996; Zahra, 1996).

Research in the field of innovation management reveal the importance of innovation activities to firms especially, SMEs. However, few literature exist on the role of human capital on innovation in SMEs in developing countries (Zhou \& Li, 2012; Helfat, 2000). It is hoped that this research will close the gap in the academic literature by finding out how innovations in SMEs are influenced by the acquisition of knowledge from education and allocation of resources to fund research and development $(R \& D)$ in the aforementioned two geographical regions.

The research is divided into four sections. First is the introduction, which includes the statement of the problem, research objectives, and research question. The second section focuses on the literature review of the variables used for the analyses in this research study. The methodology of the research, including the various models, findings, level of accuracy of forecasting, and analyses of the findings are discussed in the third section. The last section discusses the conclusion and contributions that can be drawn from the findings and the likely implications of the test results on managerial decisions making and government policy. It also gives insight into the limitations of the research and the prospects for future research.

\subsection{Problem Statement}

Firstly, the strategic innovation studies identified in the literature concentrate on the interaction between administrative and technical innovations, and their influence on firm performance, where administrative innovation is made up of the market and organizational innovations while technical innovation is made up of product and process innovations. The work of Zhou and Li (2012) investigates the relationship between the knowledge base (human capital) and radical innovations, and performance of the firm (Hamid, 2017). However, the literature does not identify which form of the knowledge base of employees' influences innovation. This research seeks to identify how the human capital of SMEs acquired by education, on-the-job training, and research and development activities influence innovation and improvement of products.

\subsection{Research Objective}

Innovation in firms has been categorized into two main parts: administrative and technical. These innovative actions are adopted by employers, managers, and employees for re-aligning the activities of a firm within a particular period of time (Olughor, 2015; Hassan, Shaukat, Nawaz, \& Naz, 2013). The study by Damanpour, Szabat, and Evan (1989) reveals that there is a significant relationship between administrative innovation and technical innovation and both play a role in determining the performance of SMEs. The research by Zhou and Li, (2012) on radical innovation, gives insight into the role played by the stock of knowledge of employees. It introduces the effect of breadth and depth of knowledge to harness the innovativeness of SMEs. However, the study does not reveal the role of knowledge acquisition, such as education, on-the-job training, and $\mathrm{R} \& \mathrm{D}$ activities play in the innovation activities of SMEs separately. This research aims to close the identified gap through the introduction of four human capital factors in SMEs to determine their impact on innovation and improvement of existing products in the market. The objective of this research is to find out the impact of the human capital factors on the innovation of products in a firm.

\subsection{Research Question}

This research helps to address the gaps identified in the aforementioned literature. The research question posed is used to address the relationship between human capital and product innovation in SMEs. That is:

- Does human capital in SMEs have influence on product innovation?

\section{LITERATURE REVIEW}

The existing literature emphasizes the importance of an organization's innovation. Innovation is an essential feature which helps SMEs maintain their market competitiveness. It is argued that for SMEs to derive optimum benefit from innovation, the implementation of innovation should be in tandem with their strategic competitive orientation (Zahra \& Covin, 1993; Damanpour, 1996). According to Karabulut (2015), the operationalization of innovation should be geared toward achieving the goal, objective, mission, and vision of the firm (Karabulut, 2015). The focus of innovation in the previous literature is directed toward variables such as: staff capability, research, and development (R\&D), networking, and size of the firm. In this study, the literature is related to (1) human capital as independent variables: expenditure of $\mathrm{R} \& \mathrm{D}$, formal training of permanent workers, percentage of skilled workers, workers with university degree, workers with high school degree, workers with inadequate education, workers compensation, labor regulation, (2) control variables: age of firm, and size of firm, and (3) dependent variable: product innovation 


\subsection{Human Capital}

For a firm to harness this potential, the knowledge base of the employees should be of high quality. The employees should have in-depth know-how of the business transaction and the technical and technological understanding of the products/services. The knowledge base of employees can be acquired through diverse means such as: on-the-job training, formal school education, industrial shared information, and knowledge acquisition on the prevailing market (Prabhu, Chandy, \& Ellis, 2005). Firms usually have a better understanding of how the market structure operates, and hence additional knowledge acquired from the marketplace enables them to expand their market share.

\subsubsection{Research and Development}

Theoretically, research and development $(\mathrm{R} \& \mathrm{D})$ ranks as an important factor in SMEs innovation. Firstly, R\&D in SMEs is directed to the internal development and external absorption of new knowledge. R\&D enables employees to acquire and enhance their technical know-how and apply their tacit knowledge in the innovation processes of the firm (Cohen \& Levinthal, 1990; Lukas \& Bell, 2000). This leads to the creation of new technology and improvement of existing technology (Atuahene-Gima \& Evangelista, 2000; Moenaert \& Sounder, 1996). The improved technology enables employees to speed up production, create new products, and improve the quality of existing products in the market. These products become difficult to imitate by other competing firms in the market (Yeoh \& Roth, 1999; Christensen, 1997; Dutta, Narasimhan, \& Rajiv, 1999).

Another important argument on $\mathrm{R} \& \mathrm{D}$ raised in this research is whether SMEs in Africa and the Middle East have the potential and capacity to engage in R\&D. The SMEs in these regions rely on the knowledge, technical know-how and technology from both government and private institutions to develop their products. Due to their inadequate internal resources, they outsource from external institutions to enable them to achieve their R\&D. The lack of strong institutions to regulate intellectual property rights, in some of the countries in these regions serves as a deterrent for SMEs to engage R\&D for product development. However, it is imperative for SMEs to explore their activities in $R \& D$ to achieve their innovativeness of products.

\subsubsection{Formal Training of Permanent Workers}

Formal training in the firm increases the technical knowledge, skills, motivation, and morale needed by employees to undertake any form of a task in any daunting condition. Employees who undergo training have in their possessing the needed skills to organize themselves in a well-behaved and organized team which makes them effective in the improvement and the innovation of quality products. As the formal training of employees enhances the quality and innovation of products, it further increases the quantity of SMEs output. An increase in output has a close linkage to profit margin, decrease in the cost of productivity and sustainability of SMEs in a competitive market (Sala, 2016; Saleem, M, \& Naseem, 2011; Barzegar \& Shahroz, 2011).

Investments in human capital in SMEs are undertaken to a large extent through the form of training of all employees. Previous research emphasizes the importance of training of employees and suggests that the costs of training should be borne by employees themselves. Researchers such as Becker (1964) argue that the acquired knowledge, skill, intellect from training can be transferred by the employees to any firm of his/her choice, which in this case, makes it reasonable for the employees to pay for the total cost of training by themselves. The job-skills possessed by the employees are used to transform and innovativeness of firms which will eventually increase their growth and performance. However, SMEs should be able to pay the cost of training in cases their employees do not have the requisite resources to undertake their personal training and development. This will help to reduce the inefficiencies that occur in the course of executing projects in the firm. For instance, firms in the United States pay the total cost of training in vocational courses for their employees (Acemoglu, 1997).

\subsubsection{Skilled Workers}

An increase in the supply of skilled workers yields a greater market for skilled-workers to complement tools and technologies which brings more advantages to firms. Skilled workers are able to create technologies that become difficult to imitate in the market. In view of this, SMEs intensifies their relative demand for skilled workers to such an extent that they are motivated to increase their success stories in the firm and industry as a whole (Acemoglu, 1998; Thoenig \& Verdier, 2003). Skilled workers, specifically researchers, produce the needed basic and pragmatic research that is essential for innovation. Another merit of skilled workers in SMEs is that they apply breakthrough and innovative ideas to produce, market and distribute new products and services. In view of this, the quality, speed and the degree of innovation among and between the industry sectors are all interconnected to the environment, significance and characteristic features of firm's high degree of skilled employees (Mason, 2013).

Skilled workers are important for competition and innovation of SMEs in the market. Skilled workers enable the development of new technologies. In many situations, new technologies are embedded in the innovation and improvement of products. For instance, new products that came out of skilled workers and technology include; the airplane, the steel furnace, the computers, the satellite, and the fiber-optic. Innovative products provide a direct measure of skilled workers. The production and improvement of products generate the demand for and 
increases the motivation of skilled workers to upgrade their efficiency in the firm (Xiang, 2005).

\subsubsection{Educated Workers with University Degree}

Due to the suitable environment and the available resource capacity to large firms, they are able to adjust their R\&D to create a break-through idea for product/service innovation. However, this opportunity is bereft of SMEs. Though small firms are able to use the acquired knowledge from the market to create new ideas to support the firm, the ideas are less likely to gather the needed strength to develop new products (Zhou \& Li, 2012). In line with this argument, this research avers that a small firm with employees possessing only formal school education is less likely to propel the required idea to cause new or significantly improved products/services.

Formal education paves the way for employees to have a full understanding and needed skills to execute complex projects. The narrower the scope of knowledge of employees, the fewer the chances available for them to generate new ideas. Knowledge of workers needs to traverse along wider and diverse disciplines. This form of knowledge and technical know-how is acquired through the adequate and effective educational system, which is usually available in high educational institutions such as the universities (Schultz, 1960). This creates the inflow of intersecting knowledge from diverse disciplines in the industry. The knowledge of the employees through university education becomes more refined and effective to generate a revolutionary idea for new and improved products/services (Kanter, 1988).

\subsubsection{Educated Workers with High School Degree}

In investigating the challenges of the quality of workers more closely, it is imperative to recognize the cognitive skill, the human capital element which has close linkage with formal education. The human capital element in this section is described as the employees in SMEs who have completed and received a high school degree certificate. This leads to a framework that education is considered as a major factor in the production and innovation in SMEs (Iyigun \& Owen, 1998).

The human capital component of most people gets to its peak at a relatively young age. This is also possible even when employees are undergoing some form of formal training on their specific job in the firm. To look at the human capital component in this regard, the amount of hours spent in education raises questions for examination. The hours and years of education are considered to increase and change the intellect, skills, reasoning, attitude, and behavior of human. Employees with some amount of education are able to transfer these acquired qualities into their field of work. These qualities, among many others, are needed to instigate the innovativeness of SMEs (McFadden, 2008).

\subsubsection{Compensation of Employees}

Compensation of employees is one of the most important factors for SMEs when new activities are to be undertaken. In situations of changes in the market environment, organization structure and quality of employees at the workplace, compensation becomes an essential factor to make firms sustainable in the market. For this reason, the availability of suitable technical know-how, skills and capability of employees are recognized when employees are well-remunerated. Employee compensation includes rewards and prizes given to employees to enhance their welfare as a result of their contributions to their required job (Iyigun \& Owen, 1998; Schultz, 1961; Acemoglu, 1997). Compensation given to employees includes: wages, salaries, bonuses, allowances, and insurances.

The compensation of employees at the workplace has a close linkage to the constant transformation of the working environment. In this situation, it has become imperative to direct the form of compensation received by employees to be in harmony with the changing environment. Each firm is endowed with unique organizational skills and culture. In the same breath, each department in a firm has organizational ethics and culture which may be different from other departments. This makes it imperative for employees to receive compensation which is in line with their work specifications. After going through all processes to select the required employees and placing them in their various field of work, it becomes important for SMEs to award the employees with suitable prizes to enhance their motivation in their specific fields of engagement.

\subsubsection{Inadequately Educated Employees}

Different opinions exist on the role education plays in the operational activities of SMEs. In the past, teaching individuals about something was regarded as a necessary form of education. In recent times, education is treated as assisting individuals to develop enough skills to enable them to understand and analyze complex issues and find their desired path in an ambiguous situation. Individuals who have little knowledge or education are unable to participate in the economic and socio-cultural activities of any institution. Little or inadequate education of employees does not necessarily imply that the employees do not have any form of knowledge, but rather they may not possess the required skills for operational activity.

Albeit the inadequate educational level of employees in SMEs, their impact on the performance (Nichter \& Goldmark, 2009) and innovativeness of the firm may not be a major challenge. Inadequately educated employees are tailored trained to execute specific operations and functions of firms. Due to their specificity of the job description, their executed functions are often bereft of major flaws. For this reason, inadequately-educated employees are transformed to enhance the operational performance and innovation activities of SMEs. 


\subsubsection{Labor Regulation}

Although prior literature has given attention to the institutional activities, little study has been conducted on whether employees' regulations affect the innovation activities of SMEs in emerging economies. Empirically, little evidence is known to support this notion. Due to the regulation of employees in the workplace, the performance and activities of SMEs will be proportionately affected. A well-developed rules and regulations, a transparent and fair labor system in the workplace all enhance the ability of workers to contribute their quota to the development of innovation in the firm (Acharya, Baghai, \& Subramanium, 2013; Ghosh, 2017).

However, the implementation of rules and regulations for employees may come with additional burden and cost to the firm. In spite of the benefits associated with labor regulations, there are little adverse effects that are faced by SMEs in emerging economies in their quest to fully rollout labor regulatory system. The process of registering is relatively expensive and complex for SMEs and new firms to incorporate in their system of work. SMEs do not find it important to divert their little resources to operationalize the regulatory system of employees, which in turn adversely affect their innovative potential.

\subsection{Firm Age}

Age of a firm is considered as the number of years a particular firm has been in existence. Formally, a firm comes into existence on the day it completes its business licensing in a regulatory institution. A firm might decide to begin its business transaction on the same day of incorporation or start on a later day. However, in informal settings, a firm will start business operations before seeking to formally license the business on a later date. In another vein, a firm undertakes business operation without any form of business or operational license. Such character of firms decides to formally incorporate their business operations with the regulatory institutions only when there is severe enforcement of the law from the government, agents and regulatory institutions. The age of the firm is used as a control variable in this research.

\subsection{Firm Size}

The size of a firm which is defined by the number of fulltime employees is important in this research for several reasons. Compared to small firms, large firms tend to have enough resources to undertake $R \& D$ to create new and/or improve existing products and services. The capacity to innovate in any industry favors large firms, due to their ability to attract and access financial credit, to give out satisfactory remuneration to highly-qualified and experienced top managers and employees, to attract foreign direct investment (FDI) to establish a strong business network, and to wield market power. Local socioeconomic institutions tend to favor large firms either, voluntary or involuntary, because of their market size and socio-economic contribution to the society (Vanhaverbeke, 2001).

However, small firms do not have the opportunity to enjoy all the various favors available to large firms. Small firms are not endowed with the requisite resources to attract high-quality knowledge base employees. Given the relatively small capacity of resources from small firms, they are perceived to lack the ability to acquire sufficient credit to inject into business activity (LiPuma, Newbert \& Doh, 2013) and R\&D, to attract resources and to fulfil their insurance in case of distress business exchange (Stinchcombe, 1965). Small firms bereft of the necessary physical and intangible resources to efficiently and effectively establish business relations and networks in the industry, especially in the informal sector. This results in a reduction in their selling power and market space, which makes the cost of the business activity to increase, a reduction in overall revenue and minimization of profit (Frederking, 2004). In view of these conditions that are endowed with small firms, local regulatory body and formal institutions give relatively more attention to large firms. In a prevailing weak governance structure, SMEs suffer more. There is also virtually no political structure, institutional framework, and socio-economic infrastructure available to support the transactions of SMEs (Puffer, McCarthy, \& Boisot, 2010; Khanna, Palepu, \& Sinha, 2005; Khanna \& Krishna, 2000; Khanna \& Palepu, 2000, 1997). These do not favor SMEs to undertake R\&D to develop new product/service and enhancement of existing business transaction.

\subsection{Product Innovation}

The concept of product innovation as described in the Organization of Economic Corporation and Development's (OECD) (2005) Oslo Manual is the "introduction of a good or service that is new or significantly improved regarding its characteristics or intended uses, which includes significant improvements in technical specifications, components and materials, incorporated software, user-friendliness or other functional characteristics." Product innovations may use new technical know-how or technologies or may be a function on the combination of new and existing technical knowhow or technologies. In this research, product innovation is used to describe the introduction of new goods and services released by firms (Gunday, Ulusoy, Kilic \& Alpkan (2011). The research by Akova, Ulusoy, Payzin, and Kaylan (1998) indicates that the process of product innovation has some driving factors which include: technological advancement, market competition, life-span of products, and customer needs.

Product innovation is described as new good and service released by firms that have characteristic features distinct from other good and service in the market. The intended uses of the product differ significantly from previously produced goods and services by the firm. For instance, the introduction of microprocessors and music players in the 
market are examples of new products with new technical know-how and technologies. The first smart-phone introduced into the market is an example of a new product with a combination of new and existing technical knowhow and technologies. A good or service can be termed as an innovation even when there is a small change in their technical specifications in their development. For instance, an existing technical specification that is formally used as an intermediary in the production of other goods is currently being used to produce new goods or services.

In view of the above reasoning, this research suggests the hypothesis below:

- H1: Human capital factors in SMEs have a significant influence on product innovation.

The eight factors of human capital are grouped into three classes through a statistical approach of principal component factor. The three classes are named as: employee's challenge (labor regulation, inadequate educated labor and compensation of employee), employee's education (university and high school degrees), and employee's development (employee training, R\&D and skilled employee).

The Figure 1 below is a pictorial view of the above hypothesis.

Independent Variables Dependent Variable

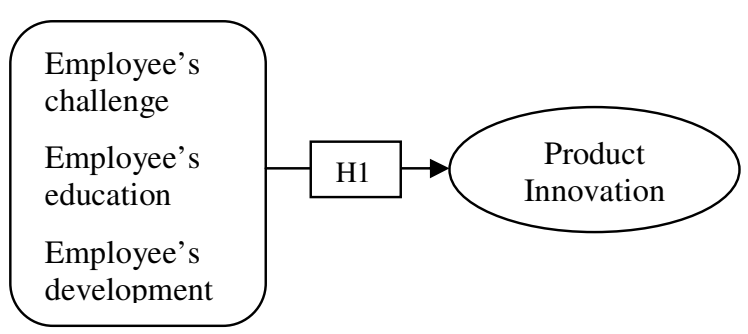

Figure 1: Research Hypothesis (Author's compilation, 2019)

\section{METHODOLOGY}

This section specifies the key variables along with the data used in this research and methods to analyse the data. For the analysis, this dissertation work uses industry-level data gathered through the World Bank Enterprise Survey (WBES) databases (The World Bank, 2018). The survey data is made up of emerging and developing economies from different geographical regions around the world. The surveys are administered between the years 2006 and 2018 with the intent to offer an insight into the innovations of firms. The WBES is one of the broad databases available to researchers. The data has been relied on and validated by other literature to indicate the role of innovation, governance, institutions, financial development and international trade on the growth of firm (Yang, 2016; LiPuma, Newbert \& Doh, 2013; Seker, 2011). The survey employs random sampling to select firms in each country, from the manufacturing and the service sectors of the economy. The sectors are stratified by size (number of employees) of the firm and geographical region. The WBES' data from different geographical regions are comparable due to the similitude in the sampling method and survey instruments employed.

The main focus of the research is to ascertain the impact of human capital on the innovation of product innovation. Data from both the manufacturing and service sectors of the economy are included from the survey. The total observation from 136,887 firms in the manufacturing and servicing sectors are collected through a stratified random sampling (The World Bank, 2005), from 138 countries in six geographical regions, namely: Sub-Saharan Africa (AFR), East Asia and the Pacific (EAP), Europe and Central Asia (ECA), Latin America and the Caribbean (LAC), the Middle East and North Africa (MNA), and South Asia region (SAR) by the survey. The research targets only SMEs in economies in AFR and MNA. The size of the firm is measured by using the number of permanent employees in the firm. Since the focus of this dissertation is on SMEs, firms with a total number of workers not more than 99, (OECD, 2005), all large firms (i.e., firms with a total number of employees of 100 and above) are removed from the data. The age of the firm is estimated as the particular date the survey a firm answered the questionnaire minus the date it started business transactions. From this estimation, the youngest firm in the research is one and the oldest firm is 212 years old. These estimations reduced the total firms observed from 136,887 to 33,977 in 53 countries.

Different drivers and forms of innovation are identified in the innovation database of WBES. These factors are put into two separate categories. The first category is a factor considered as product innovation in SMEs and is named as a dependent variable. The factors in the second category are considered as factors of human capital that influences innovation in SMEs, which are named as independent variables in this research. A total of eight factors are identified as independent variables. To determine the statistical significance of all the factors, a pairwise correlation analysis is conducted on the dependent variable and the independent variables. The dependent variable is a dummy, that is Yes $=1$, and $\mathrm{No}=0$. The independent dummy variables are: $R \& D$, formal training of permanent employees. The percentage variables are: percentage of total employees who are skilled, percentage of total employees with university degree, percentage of total employees with high school degree, inadequate educated workers. The other independent variables are the total compensation of employees and the regulation of labor.

From the many variables in WBES used to measure human capital, the research employed principal component factor (PCF) to factor and reduce the number of variables. By using the value of 1 as an eigenvalue limit point, three 
unique factors are identified from this analysis. The independent variables which are strongly related to each other and converge as one factor have their factor loadings greater than 0.3 (R-bloggers, 2018). The results from the PCF are indicated in Table 1. These three factors have converging items that are measuring similar classes. From the constructed factors, two of the factors have three items while the other factor has two items. The three classes are:

- Employee's challenge - labor regulation, inadequate educated labor and compensation of employee;

- Employee's education - university and high school degrees; and

- Employee's development - employee training, $\mathrm{R} \& \mathrm{D}$ and skilled employee.

Using the three factors together with the two control variables as independent variables regression model is created against the dependent variable and operationalized with STATA statistical software for results and analyses.

Table 1: Factor Analysis

\begin{tabular}{|l|c|c|c|}
\hline \multicolumn{1}{|c|}{ Variable } & $\begin{array}{c}\text { Employee's } \\
\text { challenge }\end{array}$ & $\begin{array}{c}\text { Employee's } \\
\text { education }\end{array}$ & $\begin{array}{c}\text { Employee's } \\
\text { development }\end{array}$ \\
\hline $\begin{array}{l}\text { Employee's challenge - } \\
\text { inadequate eduation }\end{array}$ & $\mathbf{0 . 8 2 1}$ & -0.066 & 0.020 \\
\hline $\begin{array}{l}\text { Employee's challenge - } \\
\text { regulations }\end{array}$ & $\mathbf{0 . 7 9 3}$ & -0.022 & 0.060 \\
\hline $\begin{array}{l}\text { Employee's challenge - } \\
\text { compensation (log) }\end{array}$ & $\mathbf{0 . 4 6 4}$ & 0.255 & 0.010 \\
\hline $\begin{array}{l}\text { Employee's education - } \\
\text { university degree }\end{array}$ & 0.039 & $\mathbf{0 . 7 7 9}$ & -0.036 \\
\hline $\begin{array}{l}\text { Employee's education - } \\
\text { high school degree }\end{array}$ & -0.104 & $\mathbf{0 . 7 7 6}$ & 0.097 \\
\hline $\begin{array}{l}\text { Employee's } \\
\text { development- research } \\
\text { and development }\end{array}$ & 0.034 & 0.138 & $\mathbf{0 . 7 5 3}$ \\
\hline $\begin{array}{l}\text { Employee's } \\
\text { development - formal } \\
\text { training }\end{array}$ & 0.046 & -0.060 & $\mathbf{0 . 7 5 1}$ \\
\hline $\begin{array}{l}\text { Employee's } \\
\text { development- skilled } \\
\text { employees }\end{array}$ & -0.076 & 0.098 & $\mathbf{- 0 . 3 6 0}$ \\
\hline
\end{tabular}

Principal component factor (PCF) with varimax rotation and Kaiser Normalization. $\mathrm{KMO}=53.58 \%$

Source: Author's compilation (2019)

\section{Attributes}

In this section, the variables, scale of attributes, and references are shown. These attributes are taken from both innovation literature and literature from other fields of discipline. These attributes strengthens the reliability and validity of the independent variables on the dependent variables through statistical models. The attributes are:

Employee's Challenges (Emp_Cha). Three variables are used to construct an attribute of employee's challenges based on the research studies of Acharya, Baghai, and Subramanium (2013), Ghosh (2017), Iyigun and Owen (1998), Nichter and Goldmark (2009), Schultz (1961), and Acemoglu (1997). One of the variables asks respondents to indicate the total expenditure on employees in the last accounting year. Two of the variables ask respondents to indicate on a five Likert's scale (0-no obstacle to 4-very severe obstacle) how much of an obstacle they faced with regards regulated labor and inadequately educated labor.

Employee's Educational Level (Emp_Edu). Two variables are used to construct an attribute of employee's educational level based on the research work of Kanter (1988), McFadden (2008), Schultz (1960), and Iyigun and Owen (1998). The respondents are asked to indicate on a percentage $(\%)$ the full-time employees with high school education and university degree in the firm relative to the total number of full-time employees in the firm.

Employee's Training/Skills Development (Emp_Dev). Three variables are used to construct an attribute of employee's training/skills development based on the studies of Sala (2016), Atuahene-Gima and Evangelista (2000), Lukas and Bell (2000), McDowall and Saunders (2010), Becker (1964), Acemoglu (1998), Thoenig and Verdier (2003), Gurau, Dana and Lasch (2010), and Mason (2013). Two of the variables ask respondents to identify on a dummy scale $(\mathrm{Yes}=1, \mathrm{No}=0$ ) whether formal training of employees and R\&D are undertaking in the firm. Another variable asks respondents to indicate on a percentage (\%) the number of skilled employees in the firm relative to all permanent workers in the firm.

\section{Innovation}

The variable employed to measure the innovative activity of a firm in this research study is product innovation. The attribute of innovation is in harmony with the Guidelines for Collecting and Interpreting Innovation Data from OECD's (2005). The selection of the variable is also guided by previous studies (Akova, Ulusoy, Payzin \& Kaylan, 1998; Gunday, Ulusoy, Kilic \& Alpkan, 2011). The variable ask respondents to indicate on a dummy scale (Yes $=1, \mathrm{No}=0$ ) whether their firms have in the last three years introduced any new product into the market. The "last three years" is used in the questions to help the investigators to know how firms are familiar with the constant changes in the market and consumer preference.

\subsection{Data Analyses}

This section presents the data analyses and the main findings from this research. Equally presented are the descriptive statistics, such as mean, standard deviation, minimum and maximum of all the independent and the dependent variables. This section also analyses and discusses the correlation of all independent variables with the dependent variable. The above is then followed by a discussion of the regression models, their analysis and 
outcomes. All the variables are coded to ease the presentation of statistical computations and analyses.

The coded variables are explained as follows:

- Prd_Inv: product innovation

- Emp_Cha: employee's challenges;

- Emp_Edu: employee's educational level;

- Emp_Dev: employee's training/skills development;

- Age: firm age; and

- Size: firm size (SMEs).

In the Table 3 below, the descriptive statistics of all the independent and the dependent variables are shown. It shows the total number of firms observed, the mean, standard deviation, minimum, and maximum of the five independent and the dependent variable.

Table 3: Descriptive Statistics of Dependent and Independent Variables

\begin{tabular}{|l|c|c|c|c|c|}
\hline \multicolumn{1}{|c|}{ Variable } & Obs. & Mean & $\begin{array}{c}\text { Standard } \\
\text { Dev. }\end{array}$ & Min. & Max. \\
\hline $\begin{array}{l}\text { Product } \\
\text { Innovation }\end{array}$ & 20028 & 0.383 & 0.486 & 0 & 1 \\
\hline $\begin{array}{l}\text { Employee's } \\
\text { challenge }\end{array}$ & 2577 & 0 & 1 & -2 & 3 \\
\hline $\begin{array}{l}\text { Employee's } \\
\text { education }\end{array}$ & 2577 & 0 & 1 & -3 & 11 \\
\hline $\begin{array}{l}\text { Employee's } \\
\text { development }\end{array}$ & 2577 & 0 & 1 & -2 & 3 \\
\hline $\begin{array}{l}\text { Age } \\
\text { Size (SMEs) }\end{array}$ & 243977 & 18.63 & 18.808 & 1 & 99 \\
\hline
\end{tabular}

Source: Author's compilation (2019).

3.1.1 Pairwise Correlations between Independent Variables in Human Capital and Product Innovation

This subsection discusses the results of the pairwise correlations in this research. The relationship between all the independent variables in human capital (employee's challenge, employee's education and employee's development), control variables (age and size) and the dependent variable (product innovation) are shown in Table 3. All the abbreviations used in the pairwise correlations are explained in subsection 3.1.

The results reveal positive correlation coefficients in employee's challenge (corr $=0.092)$, employee's education (corr=0.053), employee's development (corr=0.300) and size (corr $=0.052)$ are observed. However negative correlation coefficient is recorded at age (corr $=-0.015)$. The employee's challenge, employee's education, employee's development, age and size have significance levels of $\mathrm{p}$-values $(\mathrm{p}<0.05)$.
Table 3: Pairwise Correlations between Independent Variables in Human Capital and Product Innovation

\begin{tabular}{|l|c|c|c|c|c|c|}
\hline Variable & $\begin{array}{c}\text { Prd_ } \\
\text { Inv }\end{array}$ & $\begin{array}{c}\text { Emp_ } \\
\text { Cha }\end{array}$ & $\begin{array}{c}\text { Emp_ } \\
\text { Edu }\end{array}$ & $\begin{array}{c}\text { Emp_ } \\
\text { Dev }\end{array}$ & Age & Size \\
\hline Prd_Inv & 1 & & & & & \\
\hline Emp_Cha & 0.092 & 1 & & & & \\
\hline Emp_Edu & 0.053 & $0.2 \mathrm{E}-3$ & 1 & & & \\
\hline Emp_Dev & 0.3 & $0.6 \mathrm{E}-3$ & $0.6 \mathrm{E}-3$ & 1 & & \\
\hline Age & -0.015 & 0.013 & 0.118 & 0.149 & 1 & \\
\hline Size & 0.052 & 0.09 & 0.175 & 0.202 & 0.199 & 1 \\
\hline
\end{tabular}

Source: Author's compilation (2019).

\subsubsection{Regression Model}

This section presents the regression model for the independent variables and the dependent variable used in research. The regression model is created for human capital factors and product innovation. Human capital factors (employee's challenge, employee's education, and employee's development) and control variables (age and size) are used to perform these regression analyses.

For a regression model, R-squared value refers to the square of the correlation between the expected values and the computed values. It explains the degree to which the independent variables explain the variation of the dependent variable. This implies that for higher R-squared value, the variations of the independent variables explain more variations in the dependent variable. The correlation ranges from -1 to 1 , hence the $\mathrm{R}$-squared of the correlation ranges from 0 to 1 . The greater the degree of correlation between the expected values and the actual values, the greater the R-squared, irrespective of whether the correlation is positive or negative. The adjusted R-squared is a goodness-of-fit statistical test that gives an adjustment to the R-squared statistical test, such that an independent variable that is correlated to an expected or a dependent variable increases the adjusted R-squared while an independent variable with less correlation to an expected variable decreases the adjusted R-squared.

The Root mean squared error (RMSE):

$$
\text { Root MSE }=\sqrt{\frac{1}{n} \Sigma(\hat{\mathrm{y}}-\mathrm{y})^{2}}
$$

where $\hat{y}$ : computed value, and y: expected value,

is a statistical test that measures how well a model performed. It measures the relationship between the expected and the actual values. It is the root of the sum of square of differences between the expected values and the actual values in a model. The smaller the value of Root MSE, the greater the goodness-of-fit of the model. 
9 A. W. Aidoo/ Southeast Europe Journal of Soft Computing Vol. 8 No.2 2019 (1-13)

The Mean Percentage Error (MPE):

$$
\mathrm{MPE}=\frac{1}{\mathrm{n}} \sum \frac{|\hat{\mathrm{y}}-\mathrm{y}|}{\mathrm{y}}
$$

shows how big or small detected errors are when undertaking a regression model. Big percentage error implies that the statistical test result is far from the accepted values, while a small percentage error means the test results are very close to the accepted values.

The F-statistical test is explained as the ratio of two variances:

$$
\mathrm{F}=\frac{\operatorname{Var}(\hat{y})}{\operatorname{Var}(\mathrm{y})}
$$

It shows whether a linear regression model gives a better goodness-of-fit to the data. The confidence interval of a statistical test result shows the extent of uncertainty connected with a regression model. The confidence interval provides two numbers where the sample parameter is said to fall in between, combined with a statement of probability.

3.1.2.1 The Impact of Independent Variables in Human Capital on Product Innovation

The regression analysis of human capital factors (employee's challenge, employee's education, and employee's development), control variables (age and size) and dependent variable (product innovation) is shown inTable4. This is done through the regression model below in Equation 1:

Product_innovation $=\beta_{0}+\beta_{1}$ Employee's_challenge + $\beta_{2}$ Employee's_education $+\beta_{3}$ Employee's_development + $\beta_{4}$ Age $+\beta_{5}$ Size

A total number of 2,524 firms are observed. The R-squared is found as 0.128 , the root mean squared error (Root MSE) is found as 0.466 , and the mean percentage error (MPE) is 0.380 .

The impact of employee's challenge, employee's education and employee's development on product innovation are all significant, with $\mathrm{p}<0.05$.

The regression coefficients and the p-values for the independent variables in human capital are: employee's challenge $\left(\beta_{1}=0.026, \mathrm{p}=0.022\right)$, employee's education $\left(\beta_{2}=0.029, \quad \mathrm{p}=0.004\right)$, employee's development $\left(\beta_{3}=-\right.$ $0.140, \mathrm{p}=0.001)$, age $\left(\beta_{4}=-0.001, \mathrm{p}=0.253\right)$, and size $\left(\beta_{5}=0.001, \mathrm{p}=0.095\right)$.
Table 4: The Impact of Independent Variables in Human

\begin{tabular}{|c|c|c|c|c|c|}
\hline Source & SS & df & MS & $\begin{array}{c}\text { No. of } \\
\text { obs. }\end{array}$ & 2524 \\
\hline & & & & $\begin{array}{l}\mathrm{F}(21, \\
2502)\end{array}$ & 17.45 \\
\hline Model & 79.465 & 21 & 3.784 & Prob $>F$ & 0.000 \\
\hline \multirow{2}{*}{ Residual } & 542.621 & 2502 & 0.217 & R-sq. & 0.128 \\
\hline & & & & $\begin{array}{c}\text { Adj. R- } \\
\text { sq. }\end{array}$ & 0.120 \\
\hline \multirow[t]{2}{*}{ Total } & 622.086 & 2523 & 0.247 & RMSE & 0.466 \\
\hline & & & & MPE & 0.380 \\
\hline Variables & Coef. & $\begin{array}{l}\text { Std. } \\
\text { Err. }\end{array}$ & T-test & $\begin{array}{c}P- \\
\text { value }\end{array}$ & Conf. Int. \\
\hline Emp_Cha & 0.026 & 0.011 & 2.290 & 0.022 & $\begin{array}{l}0.004, \\
0.048\end{array}$ \\
\hline Emp_Edu & 0.029 & 0.010 & 2.850 & 0.004 & $\begin{array}{l}0.009 \\
0.049 \\
\end{array}$ \\
\hline Emp_Dev & 0.140 & 0.010 & 14.160 & 0.001 & $\begin{array}{l}0.121, \\
0.160\end{array}$ \\
\hline Age & -0.001 & 0.001 & -1.140 & 0.253 & $\begin{array}{c}-0.002 \\
0.001\end{array}$ \\
\hline Size & 0.001 & $0.1 \mathrm{E}-3$ & 1.670 & 0.095 & $\begin{array}{c}0.1 \mathrm{E}-3 \\
0.002\end{array}$ \\
\hline Constant & 0.460 & 0.069 & 6.670 & 0.001 & $\begin{array}{l}0.325 \\
0.596 \\
\end{array}$ \\
\hline
\end{tabular}
Capital on Product Innovation

Note: Country fixed effect - Yes; Industry fixed effect - Yes

Source: Author's compilation (2019).

\subsubsection{Forecasting Through Regression Model}

After undertaking the OLS regression model to determine the statistically significant impact of the independent variables on the dependent variable, this regression model is used to predict the values of the dependent variables. The regression coefficients are used to compute (i.e., through the function of sumproduct in excel) the calculated value, $Y_{c}$. A threshold $\varepsilon$ is decided to distinguish 0 and 1 from the calculated value in decimals.

Assume the value of the independent human capital variables $\left(x_{1}, x_{2}, x_{3}, x_{4}, x_{5}\right)$ are supplied, and the corresponding regression coefficients are $\left(\beta_{0}, \beta_{1}, \beta_{2}, \beta_{3}, \beta_{4}, \beta_{5}\right)$. The OLS regression model is constructed as:

$$
Y_{c}=\beta_{0}+\beta_{1} x_{1}+\beta_{2} x_{2}+\beta_{3} x_{5}+\beta_{4} x_{5}+\beta_{5} x_{5}
$$

The calculated values $Y_{c}$ are transformed into dummy variable, $Y_{p}$ :

$$
Y_{p}=\left[\begin{array}{ll}
1, & Y_{c} \geq \varepsilon \\
0, & Y_{c}<\varepsilon
\end{array}\right]
$$

The error of the forecasting is calculated by:

$$
\text { Error }=\left[\begin{array}{ll}
0, & Y_{p}=Y_{\text {exp }} \\
1, & Y_{p} \neq Y_{\text {exp }}
\end{array}\right]
$$


Accuracy of the forecasting is calculated by:

$$
\text { Acc. }=1-\frac{\Sigma \text { Error }}{N}
$$

where $N$ is the number of observations, $Y_{\text {exp }}$ is the expected value (i.e., the value of the dependent variable in the data), and Acc. is the accuracy of forecasting.

Recall that the predicted value is given by:

$$
Y_{p}=\left[\begin{array}{ll}
1, & Y_{c} \geq \varepsilon \\
0, & Y_{C}<\varepsilon
\end{array}\right]
$$

Therefore, if $Y_{p}=1$, the firm whose data is supplied is potentially a firm with a product innovation (i.e., new product). If $Y_{p}=0$, potentially the product innovation is not possible in the firm.

Policy Proposal

The independent variable values $x_{1}, x_{2}, x_{3}, x_{4}$, and $x_{5}$ are moved around the reported values and the effects on $Y_{c}$ are observed. When $Y_{c}$ is reached to a value $Y \geq \varepsilon$ then the region of these values of $x_{1}, \ldots x_{5}$ are reported to the firm. If the firm improves the existing values to those values that give $Y_{p} \geq \varepsilon$, the firm will therefore has the potential to produce new products.

3.1.3.1 Forecasting the Impact of Human Capital Factors on Product Innovation

The Table 5 shows the prediction of the possibility of introduction of a new product by a firm given the available human factors in this firm. The level of accuracy for the forecast of a product innovation through the regression model in Equation 1 is found as $63.18 \%$ when a $\varepsilon=0.535$ threshold is used.

Table 5: Forecasting the Impact of Human Capital Factors on Product Innovation

\begin{tabular}{|c|c|c|c|c|c|c|c|c|c|c|c|}
\hline N. Prd. Exp. & 0.596 & 0.026 & 0.029 & 0.140 & -0.001 & 0.001 & \multicolumn{2}{|c|}{ Cal. Val. N. Prd. Forc. } & Error & Accuracy \\
\hline 1 & 1 & 2.18 & -1.01 & 1.10 & 8 & 8 & 0.776 & 1 & 0 & $63.18 \%$ \\
\hline 0 & 1 & 0.08 & -0.02 & 0.76 & 10 & 10 & 0.703 & 1 & 1 & \\
\hline 0 & 1 & -0.27 & 0.70 & -0.65 & 19 & 19 & 0.516 & 0 & 0 & Threshold \\
\hline 0 & 1 & -0.16 & 0.67 & 0.67 & 18 & 18 & 0.703 & 1 & 1 & 0.535 \\
\hline 0 & 1 & 0.97 & -0.80 & 0.97 & 4 & 4 & 0.734 & 1 & 1 & \\
\hline 0 & 1 & 0.91 & 0.48 & -0.42 & 10 & 10 & 0.573 & 1 & 1 & \\
\hline 1 & 1 & 1.37 & -0.47 & -0.46 & 8 & 8 & 0.553 & 1 & 0 & \\
\hline 1 & 1 & 0.29 & 0.12 & -0.63 & 7 & 7 & 0.518 & 0 & 1 & \\
\hline 1 & 1 & -0.44 & 0.89 & -0.50 & 5 & 5 & 0.539 & 1 & 0 & \\
\hline 0 & 1 & 0.23 & -0.98 & -0.41 & 22 & 22 & 0.514 & 0 & 0 & \\
\hline 0 & 1 & -0.52 & -0.24 & 0.90 & 4 & 4 & 0.701 & 1 & 1 & \\
\hline 0 & 1 & 0.44 & 0.98 & 1.00 & 29 & 29 & 0.774 & 1 & 1 & \\
\hline 0 & 1 & 1.20 & -0.25 & -0.42 & 30 & 30 & 0.558 & 1 & 1 & \\
\hline 1 & 1 & 0.88 & -0.65 & 1.00 & 22 & 22 & 0.739 & 1 & 0 & \\
\hline
\end{tabular}

Author's compilation (2019)

\section{DISCUSSION AND CONCLUSION}

This section discusses the implications from the findings of the impact of the human capital factors on product innovation, and the level of accuracy of forecasting through the regression model. The limitations and areas for further research are also discussed in this section.
4.1 Main Effect of Human Capital on Innovation as Seen in the Regression Model

This subsection of the research is focused on the result of the hypothesis which is derived from the regression analysis with a model in Equation 1. It looks at the impact of human capital factors on product innovation with regards to the defined hypothesis.

(H1) Human Capital in SMEs Has a Significant Influence on Product Innovation

The hypothesis (H1) claims that human capital is efficient in the creation of a breakthrough idea for innovation of the product. The results from the regression model in Equation 1 reveal that the factors of human capital have a positive and significant impact on product innovation. In examining the factors of human capital which predicts product innovation, as in H1a; employee's challenge has a positive regression coefficient $\left(\beta_{1}=0.026\right)$, a standard error of 0.011 , and a high statistically significance level with a p-value of 0.022 . At a $95 \%$ level of confidence, confidence interval of the regression coefficient of employee's challenge is $(0.004,0.048)$. For H1b, employee's education, has a positive regression coefficient $\left(\beta_{2}=0.029\right)$, a standard error of 0.010 and a high statistically significance level with a p-value of 0.004 . At a $95 \%$ level of confidence, confidence interval of the regression coefficient of employee's education is $(0.009$, 0.049). For H1c, the employee's development shows a positive regression coefficient $\left(\beta_{3}=0.140\right)$, a standard error of 0.010 and a high significance level with a p-value of 0.001 . At a $95 \%$ level of confidence, confidence interval of the regression coefficient of employee's development is $(0.121,0.160)$.

The results of the regression analysis in Equation 1 reveal that with a total number of 2,524 firms observed, the proportion of change in the dependent variable (product innovation) that is explained by the independent variables (R-squared) is found as 0.128 . The above analysis of the regression model shows that the factors of human capital have a significant impact on product innovation in SMEs. This is a confirmation of this research's first hypothesis (H1).

\section{Forecasting Through Regression Model for Innovation}

The findings of the forecasting through regression model are shown in this subsection. The degree of accuracy of the calculated value that is forecasted through the regression model is discussed. The regression coefficients of the three independent variables in factors of human capital, the two control variables and the constants are used to estimate and analyse the power of forecasting.

The forecast for a product innovation is accurately at $63.18 \%$ through the regression model in Equation 1 when a threshold of $\varepsilon=0.535$ is used. 


\subsection{Contributions and Implications}

Based on the examination of the regression analyses, the results show a significant impact of the factors of human capital on product innovation. As the results conclude, the impact of human capital on product innovation is positive and significant. This research contributes to the understanding of the on-going discussions with regards to the relationship and the impact of the factors of human capital on product innovation. Managers have to find all the necessary inputs that have positive contributions to the firm. Again, managers have to understand and ascertain at what amount of the diverse human capital inputs are needed to spearhead the objective of the firm. The findings from this research will enable the government to understand which directive or policy is needed to enhance the capacity of human capital in both SMEs and vulnerable firms which intend to innovate.

The limitations give an opportunity for the conduct of future research studies. Future research can focus on other forms of innovation in the firm, such as: process innovation, market innovation, and organizational innovation. Since the research is undertaken from the perspective of SMEs, the results give no information on how the human capital has impacted each of the categories of the SMEs separately. For instance, based on the number of employees, firms can be categorized into micro, small, medium and large. Future research can focus on only one of the categories and analyze the impact of human capital on their innovation.

\section{REFERENCES}

Acemoglu, D. (1997). Training and Innovation in an Imperfect Labour Market. Review of Economic Studies, 64, 445-464.

Acharya, V., Baghai, R., \& Subramanium, K. (2013). Labor Laws and Innovation. Journal of Law and Economics, 56, 997-1037.

Akova, B., Ulusoy, G., Payzin, E., \& Kaylan, A. R. (1998). New Product Development Capabilities of the Turkish Electrononics Industry. Fifth International Product Development Management Conference (pp. 863876). Como, Italy: Institute of Electrical and Electronics Engineers.

Atuahene-Gima, K., \& Evangelista, F. (2000). Crossfunctional Influence in New Product Development: An Exploratory Study of Marketing and R\&D Perspectives. Management Science, 46(10), 1269-1284.

Barzegar, N., \& Shahroz, F. (2011). A Study on the Impact of the Job Training Courses on the Staff Performance. Social and Behavioral Sciences, 29, 1942-1949.

Becker, G. S. (1964). Crime and Punishment: An Economic Approach. Journal of Political Economy, 76, 169-217.
Christensen, C. M. (1997). The Innovator's Dilemma: When New Technologies Cause Great Firms to Fail. Boston: Harvard Business School Press.

Cohen, W. M., \& Levinthal, D. A. (1990). Absorptive Capacity: A New Perspective on Learning and Innovation. Administrative Science Quarterly, 35(1), 128-152.

Damanpour, F. (1996). Organizational Complexity and Innovation: Developing and Testing Multiple Contingency Models. Management Science, 42(5), 693-719.

Damanpour, F., Szabat, K. A., \& Evan, W. M. (1989). The Relationship between Types of Innovation and Organizational Performance. Journal Management Studies, 26(6), 587-601.

Dougherty, D., \& Hardy, C. (1996). Sustained Product Innovation in Large, Mature Organizations: Overcoming Innovation-to-organization Problems. Academy of Management Journal, 39, 1120-1153.

Dutta, S., Narasimhan, O., \& Rajiv, S. (1999). Success in High-Technology Markets: Is Marketing Capability Critical? Marketing Science, 18(4), 547-568.

Frederking, L. C. (2004). A Cross-national Study of Culture, Organization and Entrepreneurship in three Neighbourhoods. Entrepreneurship \& Regional Development, 16, 197-215.

Galunic, D. C., \& Rodan, S. (1998). Resource Recombination in the Firm: Knowledge Structures and the Potential for Schumpeterian Innovation. Strategic Management Journal, 19, 1193-1201.

Ghose, A. K. (2011). Trade, Foreign Capital and Development. Economic and Political Weekly, 46(28), 6771.

Gunday, G., Ulusoy, G., Kilic, K., \& Alpkan, L. (2011). Effects of Innovation Types on Firm Performance. International Journal of Production Economics, 133(2), 1365-1379.

Gurau, C., Dana, L. P., \& Lasch, F. (2010). Human Capital for Successful Entrepreneurial Ventures: The Profile of the Top Management Team (TMT) in UK Biopharmaceutical SMEs. International Journal of Entrpreneurship and Small Business, 11(4), 436-454.

Hamid, Z. (2017). Impact of High-performance Work Systems on Export-oriented SMEs Performance: The Mediating Role of Human Capital Development. The South East Asian Journal of Management, 11(2), 142-163.

Hassan, M. U., Shaukat, S., Nawaz, M. S., \& Naz, S. (2013). Effects of Innovation Types on Firm Performance: An Empirical Study on Pakistan's Manufacturing Sector. Pakistan Journal of Commerce and Social Sciences, 7(2), 243-262.

Helfat, C. E. (2000). Guest Editor's Introduction to the Special Issue: The Evolution of Firm Capabilities. Strategic Management Journal, 21, 955-959. 
Hitt, M. A., Hoskisson, R. E., Johnson, R. A., \& Moesel, D. D. (1996). The Market for Corporate Control and Firm Innovation. Academy of Management Journal, 39(5), 1084-1119.

Iyigun, M. F., \& Owen, A. L. (1998). Risk and Entrepreneurship, and Human Capital Accumulation. The American Economic Review, 88(2), 453-457.

Kanter, R. M. (1988). When a Thousand Flowers Bloom: Structural, Collective and Social Conditions for Innovation in Organizations. In B. M. Staw, \& L. L. Cummings, Research in Organizational Behavior (Vol. 10) (pp. 162211). Greenwich, CT: JAI Press.

Karabulut, A. T. (2015). Effects of Innovation Strategy on Firm Performance: A Study Conducted on Manufacturing Firms in Turkey. Procedia - Social and Behavioral Sciences, 195, 1338-1347.

Khanna, T., \& Krishna, P. (2000). The Future of Business Groups in Emerging Markets: Long-run Evidence from Chile. Academy of Management Journal, 43, 268-285.

Khanna, T., \& Palepu, K. (1997). Why Focused Strategies may be Wrong for Emerging Markets. Harvard Business Review, 75, 41-51.

Khanna, T., \& Palepu, K. (2000). Is Group Affiliation Profitable in Emerging Markets? An Analysis of Diversified Indian Business Groups. Journal of Finance, $55,867-891$.

Khanna, T., Palepu, K., \& Sinha, J. (2005). Strategies to Fit Emerging Markets. Harvard Business Review, 83, $63-$ 74.

LiPuma, J. A., Newbert, S. L., \& Doh, J. P. (2011). The Effects of Institutional Quality on Firm Export Performance in Emerging Economies: A Contingency Model of Firm Age and Size. Small Business Economics, $40,817-841$.

Lukas, B. A., \& Bell, S. J. (2000). Strategic Market Position and R\&D Capability in Global Manufacturing Industries. Industrial Marketing Management, 29(6), 565574.

Mason, P. L. (2013). Opting for Innovation: Selecting Highly Skilled Workers as a Competitive Strategy in the Jamaican Economy. Social and Economic Studies, 64(1), 115-150.

McFadden, D. (2008). Capital Accumulation and Depreciation. Review of Agricultural Economics, 30(3), 379-385.

Miller, D. (1983). Entrepreneurship Correlates in Three Types of Firms. Management Sciences, 29, 770-791.

Moenaert, R. K., \& Sounder, W. E. (1996). Context and Antecedents of Information Utility at the R\&D/Marketing Interface. Management Science, 42(11), 1592-1610.
Nichter, S., \& Goldmark, L. (2009). Small Firm Growth in Developing Countries. World Development, 37(9), 14531464.

OECD. (2005). Oslo Manual: Guidelines for Collecting and Interpreting Technology Innovation Data (3rd Ed). Paris: OECD Publishing.

OECD. (2005). Small and Medium-sized Enterprises. Retrieved from OECD - Glossary of Statistical Terms: https://stats.oecd.org/glossary/detail.asp?ID=3123

Olughor, R. J. (2015). Effects of Innovation on the Performance of SMEs Organizations in Nigeria. Management, 5(3), 90-95.

Prabhu, J. C., Chandy, R. K., \& Ellis, M. E. (2005). The Impact of Acquisitions on Innovation: Poison Pill, Placebo or Tonic? Journal of Marketing, 69(1), 114-130.

Puffer, S. M., McCarthy, D. J., \& Boisot, M. (2010). Entrepreneurship in Russia and China: The Impact of Formal Institutional Voids. Entrepreneurship Theory and Practice, 32, 441-467.

R-bloggers. (2018, April 18). P is for Principal Compnents Analysis (PCA). Retrieved from R-bloggers: R news and tutorials: https://www.r-bloggers.com/p-is-for-principalcomponents-analysis-pca/

Sala, M. R. (2016). The Impact of Training and Development on Employees Performance and Productivity. A Case Study of Jordanian Private Sector Transportation Companies Located in the Southern Region of Jordan. A Particular Reference is made to the Governance of Maan. International Journal of Management Sciences and Business Research, 5(7), 36-70.

Saleem, Q., M, S., \& Naseem, A. (2011). Degree of Influence of Training and Development on Employee's Behavior. International Journal of Computing and Business Research, 2(3), 2229-6166.

Schultz, T. W. (1960). Capital Formation of Education. Journal of Political Economy, 68(6), 571-583.

Schumpeter, J. A. (1934). Theory of Economic Developemnt. Cambridge: Harvard University Press.

Seker, M. (2011). Importing, Exporting and Innovation in Developing Countries. World Bank Enterprise Analysis Unit, 1-35.

Stinchombe, A. (1965). Social Structures and Organizations. In J. G. March, Handbook of Organizations (pp. 142-193). Chicago: Rand McNally.

Sundbo, J. (1998). The Theory of Innovation: Entreprenuers, Technology and Strategy. Cheltenham: Edward Elgar.

The World Bank. (2005). Survey Methodology. Retrieved from Enterprise Surveys: https://www.enterprisesurveys.org/methodology 
13 A. W. Aidoo/ Southeast Europe Journal of Soft Computing Vol. 8 No.2 2019 (1-13)

The World Bank. (2018). Full Survey Data. Retrieved from Enterprise Surveys:

https://www.enterprisesurveys.org/portal/login.aspx

Thoenig, M., \& Verdier, T. (2003). A Theory of Defensive Skill-biased Innovation and Globalization. American Economic Review, 93, 709-728.

Vanhaverbeke, W. (2001). Realizing New Regional Core Competencies: Establishing a Customer-oriented SME Network. Entrepreneurship \& Regional Development, 13, 97-116.

Xiang, C. (2005). New Goods and the Relative Demand for Skilled Labor. The Review of Economics and Statistics, 87(2), 285-298.

Yang, J. S. (2016). The Governance Environment and Innovative SMEs. The World Bank, November 8, 1-27.

Yeoh, P. L., \& Roth, K. (1999). An Empirical Analysis of Sustained Advantage in the U.S. Pharmaceutical Industry: Impact of Firm Resources and Capabilities. Strategic Management Journal, 20(7), 637-653.

Zahra, S. A. (1996). Governance, Ownership and Corporate Entrepreneurship: The Moderating Impact of Industry Technological Opportunities. Academy of Management Journal, 39(6), 1713-1735.

Zahra, S. A., \& Covin, J. G. (1993). Business Strategy, Technology Policy and Firm Performance. Strategic Management Journal, 14(6), 451-478.

Zhou, K. Z., \& Li, C. B. (2012). How Knowledge Affects Radical Innovation: Knowledge Base, Market Knowledge Acquisition and Internal Knowledge Sharing. Strategic Management Journal, 33(9), 1090-1102. 